\title{
Development of low-friction and wear-resistant surfaces for low-cost Al hot stamping tools
}

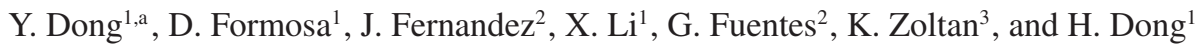 \\ ${ }^{1}$ School of Metallurgy and Materials, University of Birmingham, B15 2TT Birmingham, UK \\ ${ }^{2}$ AIN Asociación de la Industria, 31191 Navarre, Spain \\ ${ }^{3}$ S.C. PLASMATERM S.A. Tg.Mures, Romania
}

\begin{abstract}
In this study, advanced surfaces and coatings have been developed using plasma thermochemical treatment, PVD coating, electroless Ni-BN plating and duplex surface engineering to produce low-friction and wear-resistant surfaces for cast iron stamping tools. Their microstructural and nano-mechanical properties were systematically analysed and the tribological behaviour of these new surfaces and coatings were evaluated. The experimental results have shown that under dry sliding condition, the tribological behaviour of aluminium differed great from that of steel regardless of the counterpart material. Highly reactive aluminium had a strong tendency to solder with tool surfaces during dry sliding. However, the lubricity of gray cast irons can be significantly improved by Ni-BN and DLC coatings. The coefficient of friction reduced from about 0.5 for untreated cast irons to about 0.2 sliding against aluminium. Duplex treatment combining plasma nitrocarburising with lowfriction coatings showed superior durability than both DLC and Ni-BN coatings.
\end{abstract}

\section{Introduction}

Metal stamping process is widely used for production of thin-wall products such as vehicle body panels because of its high productivity. For example, in a typical car body, there are 40-50 major panels produced by 150-250 die sets [1]. Current hot stamping tools for forming aluminium alloys are normally made of hot work tool steels, such as H13. Hot stamping tools are costly because of the high materials price (expensive hot work tool steels) and manufacturing costs (poor formability and machinability). The tool cost could be reduced by the use of low-cost cast irons with good castability and machinability. However, cast irons lack of adequate hardness $(<350 \mathrm{HB})$ and die wear is a major concern. Consequently, it is a major technological challenge how to produce low-friction and wear-resistant cast iron stamping tools.

Surface engineering has been proved to be one of the most effective means to improve the surface properties of a wide range of engineering materials and extend the service life many engineering components [2-4]. Die coatings and surface treatment such as nitriding, hardfacing, and CVD carbide have been used to reduce the wear and scoring of steel die surface, and increase longevity for forming

\footnotetext{
${ }^{\text {a }}$ Corresponding author: yangchun.dg@gmail.com
}

This is an Open Access article distributed under the terms of the Creative Commons Attribution License 4.0, which permits unrestricted use, distribution, and reproduction in any medium, provided the original work is properly cited. 


\section{MATEC Web of Conferences}

Table 1. Sample code and the corresponding surface treatments.

\begin{tabular}{|c|c|c|c|c|c|}
\hline $\begin{array}{c}\text { Sample } \\
\text { code }\end{array}$ & PNC & Ni-BN & Ni-BN $(\mathrm{PH})$ & DLC & PNC/ Ni-BN \\
\hline $\begin{array}{c}\text { Surface } \\
\text { treatment }\end{array}$ & $\begin{array}{c}\text { plasma } \\
\text { nitrocarburising }\end{array}$ & $\begin{array}{c}\text { electroless } \\
\text { plating }\end{array}$ & $\begin{array}{c}\text { post hardened } \\
\text { Ni-BN }\end{array}$ & $\begin{array}{c}\text { PVD diamond } \\
\text { like carbon }\end{array}$ & $\begin{array}{c}\text { duplex of } \\
\text { PNC/Ni-BN }\end{array}$ \\
\hline
\end{tabular}

tool. For instance, Toyota diffusion (TD) coated D2 steel dies can stamp over 40000 B-pillar inners [5] and CVD TiC coating can improve the tool life by $60 \%$ compared to its uncoated counterpart; solid lubricants such as $\mathrm{MoS}_{2}$ were integrated into coating systems to improve its lubricity [6]. Fraser and Jahedi investigated alumina coating to prevent adhesion and soldering on Al-11Si-3Cu die-casting [7], and Mendez proposed model of heat transfer of solid lubricant on hot dies [8]. Thermochemical treatments have shown potential in improving the wear, corrosion resistance and fatigue of cast iron die surfaces $[9,10]$. However, little work has been reported on the tribological behaviour of surface engineered cast irons sliding against aluminium alloys.

In this study, plasma nitrocarburising (PNC) was used to increase the surface hardness and load bearing capacity of gray cast iron, self-lubricating Ni-BN and diamond-like carbon (DLC) coatings were deposited using electroless plating and PVD respectively and a duplext surface system was designed by combining PNC with Ni-BN. Their microstructural and nano-mechanical properties were systematically characterised using SEM and nanoindentation; the tribological behaviour of these new surfaces and coatings were evaluated using pin-on-disc tribometers using Al-6082 flat-end pin and hardened steel ball. Post-test examination was conducted to study the wear surfaces.

\section{Material and method}

The substrate material was gray cast iron G3500 with the chemical composition (wt \%): 3.29C, 1.19Si, $0.54 \mathrm{Mn}, 0.48 \mathrm{Cr}, 0.44 \mathrm{Mo}$ and balance $\mathrm{Fe}$. The hardness is $195-234 \mathrm{HBW}$ and the tensile strength is $498 \mathrm{MPa}$. Flat samples of gray cast iron G3500 were ground, polished and acetone cleaned prior to treatment. Treated sample is summarised in Table 1. Low-temperature plasma nitrocaburising (PNC) was conducted in standard DC plasma furnace (Klöckner $40 \mathrm{~kW}$, Germany), using a gas mixture (50\% $\mathrm{H}_{2}, 48 \% \mathrm{~N}_{2}$ and $2 \% \mathrm{CH}_{4}$ ) at a pressure of 4 mbar at $575^{\circ} \mathrm{C}$ for 4 hours. Process parameters have been optimized based on the previous studies [11, 12]. Untreated and PNC treated samples were electroless plated with a new Ni-BN nanocomposite coating. Some Ni-BN coatings were post hardened at $190{ }^{\circ} \mathrm{C}$ for 3 hours. DLC film was prepared by PVD using a standard commercial process at Asociación de la Industria, Spain.

The layer structure and composition of the engineered G3500 surfaces were examined by scanning electron microscope (SEM, JEOL 7000) equipped with an EDS. Nano-indentation (Micro Materials Ltd) and Vickers microhardness (Mitutoyo mVK-H1 micro) was used to measure the surface hardness of the treated surfaces by following ASTM E92 standard.

Pin on disk linear reciprocating tribometer (TE79, Phoenix tribology, UK) was used to assess the coefficient of friction $(\mathrm{CoF})$ at room temperature. ASTM G99 standard was used as a reference [13]. Two types of counterpart surfaces were used to sliding against the engineered surfaces: flat-end Al 6082 pin and hardened steel (HS) ball. During the tests, the flat end Al 6082 pin $(\varnothing 6 \mathrm{~mm})$ reciprocated against the sample surface under $5 \mathrm{~kg}(1.8 \mathrm{MPa})$ and $0.2 \mathrm{~kg}(0.07 \mathrm{MPa})$. A self-aligning system was used to ensure the full contact between the pin and the sample surfaces as shown in Fig. 1. The sliding stroke length of the pin was $3 \mathrm{~mm}$ and the speed was $0.3 \mathrm{~mm} / \mathrm{s}$, and a new pin was used for each test. A steel ball $(\varnothing 12 \mathrm{~mm})$ was used to test the wear of engineered surfaces under $100 \mathrm{~g}(337 \mathrm{MPa})$ and $200 \mathrm{~g}$ (481 MPa). Wear morphology was examined using SEM and the elements in wear scars were analysed by EDS. 

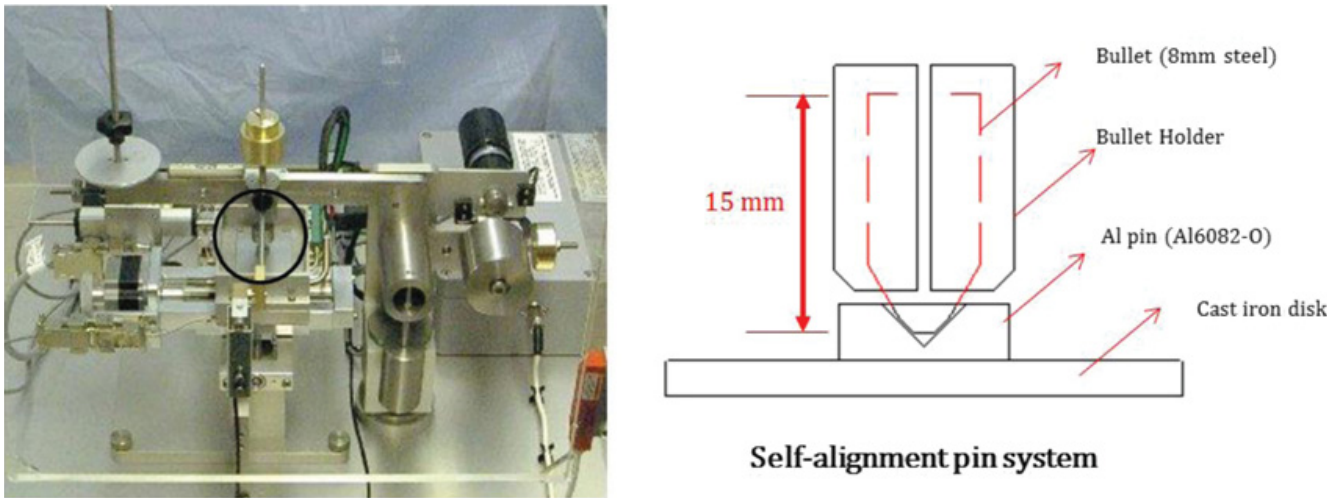

\section{Self-alignment pin system}

Figure 1. Setting up of reciprocating friction coefficient test.

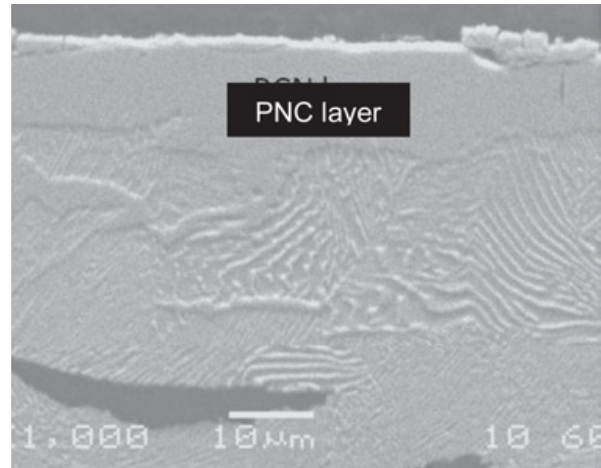

(a)

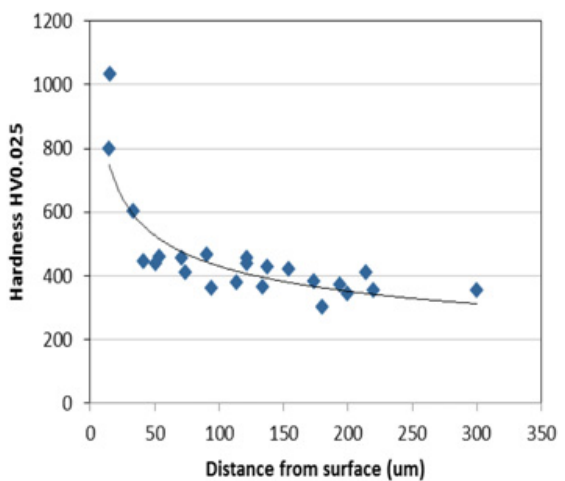

(b)

Figure 2. SEM picture of the near-surface area of gray cast iron sample after plasma nitrocarburising at $575{ }^{\circ} \mathrm{C}$ for 4 hours. Etchant: $2 \%$ nital (a), and chemical composition of surface (b).

\section{Results and discussion}

\subsection{Materials microstructure}

\subsubsection{Plasma nitrocarburised cast iron}

The typical metallographic microstructure of plasma nitrocarburised G3500 gray cast iron is shown in Fig 2a. It can be seen that the compound layer, with thickness of about $15 \mu \mathrm{m}$ is very uniform and compact without significant defect. Hardness of the compound layer is around $1100 \mathrm{HV}$ and quickly droped to about $650 \mathrm{HV}$ at depth of $15 \mu \mathrm{m}$. The thickness of the diffusion zone was estimated by hardness-depth profile to be approximately $200 \mu \mathrm{m}$ but it is not so clear under SEM.

The compound layer is very thin and it can be ground after treatment because of its brittleness. The compound zone cannot pass over flakes of graphite, like that of gas nitrocarburising [14]. There are a number of observations proving that the plasma process and gas process on cast iron produce compound layer being similar in layer depth however plasma process has smaller surface roughness changes than in the gas process. 


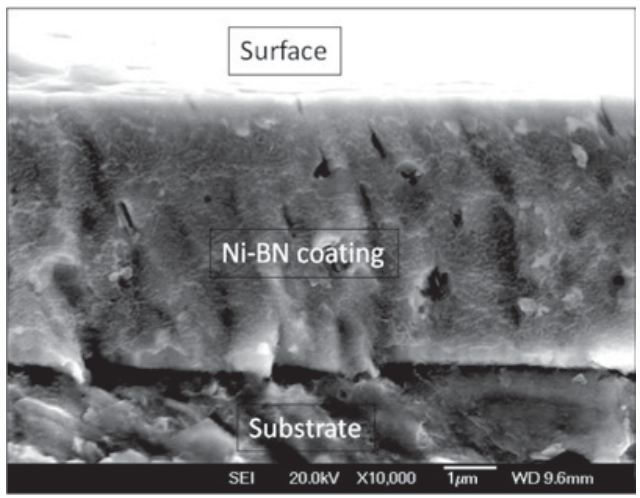

(a)

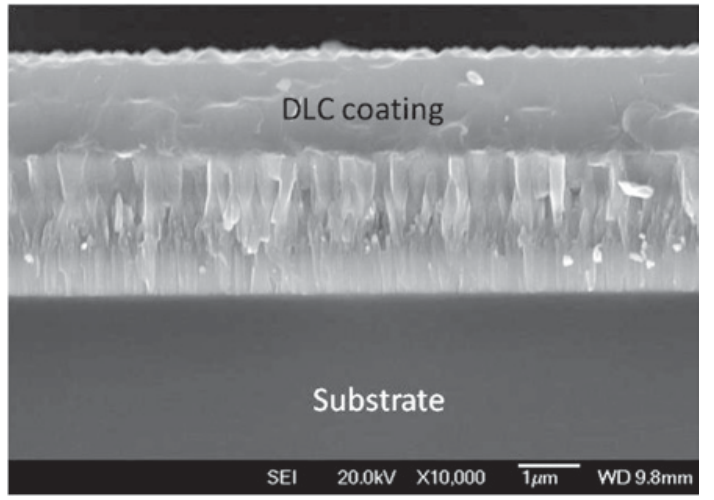

(b)

Figure 3. FESEM fractography of Ni-BN (a) and DLC (b) coated surfaces.

\subsubsection{Self-Iubrication coating}

Electroless plated Ni-BN is a mono layer nickel-based composite coating doped with h-BN particles. The fractography (cross-sectional fracture image) shows that the coating is approximately $5 \mu \mathrm{m}$ thick (Fig. 3a). EDX analysis revealed that the coating consists of $6.6 \mathrm{wt} \% \mathrm{P}, 5 \mathrm{wt} \% \mathrm{~B}, 4.5 \mathrm{wt} \% \mathrm{C}$ and bal. Ni. As shown in Fig. 3, the Ni-BN coating is quite dense although it contains some dark pits and white particles. No notable composition difference between the pits and the matrix could be probed by EDX.

The fractography of DLC is shown in Fig. 3b. It can be seen that the DLC coating is densely packed, without any cracking or delamination within the coating or at the interfaces of layer-substrate. This DLC coating is composed of two sub-layers. The top layer is DLC film with a thickness of $1.5 \mu \mathrm{m}$ and the bonding layer beneath is a columnar structured $\mathrm{CrN}$ layer with a thickness of $2 \mu \mathrm{m}$. EDS composition analyse confirmed that the DLC layer contained $70 \mathrm{at} \% \mathrm{C}, 7 \mathrm{at} \% \mathrm{~N}$ and a high amount of oxygen on the top surface probably due to contamination [15]. The bonding layer contained $45 \mathrm{at} \% \mathrm{Cr}, 28 \mathrm{at} \% \mathrm{~N}$ and the rest carbon.

\subsection{Tribology}

\subsubsection{Friction of surface treated cast iron}

Figure 4a summarised the mean coefficient of friction (CoF) during 20 strokes of flat-end Al-6082 pin sliding against surface engineered as well as untreated cast iron for comparison. It can be seen that untreated and PNC treated G3500 showed a similar very high CoF of 0.45-0.50, which can be effectively reduced by all the surface treatments investigated in the study. As evidenced in Fig. 4a, the coefficient of friction of Ni-BN coating is $0.20-0.25$ and when post-hardened, the Ni-BN (PH) coating revealed a slightly lower $\mathrm{CoF}$ of about 0.18 when compared with the as deposited Ni-BN. DLC coatings showed the lowest $\mathrm{CoF}$ of about 0.15 .

An important tribological feature observed in the sliding wear of aluminium can be illustrated by low speed dry sliding in this study. The fact that aluminium is highly reactive and able to solder onto substrate under high pressure led to quick increase in $\mathrm{CoF}$ value and large fluctuation. Post-test examination revealed a large area of aluminium transferred onto the tested surfaces with a grey colour (Fig. 4b). Both the untreated and PNC treated surfaces showed very high FoC over time. This implies that the wear of aluminium was accompanied by the generation of a transferred $\mathrm{Al}$ film on the cast iron surfaces. Once the transfer film is created, the pin ends up running on a film of its own material-Al. As pressure increased from 0.35 to $1.8 \mathrm{MPa}$, more transfer of aluminium occurred as a result of larger contact area. 


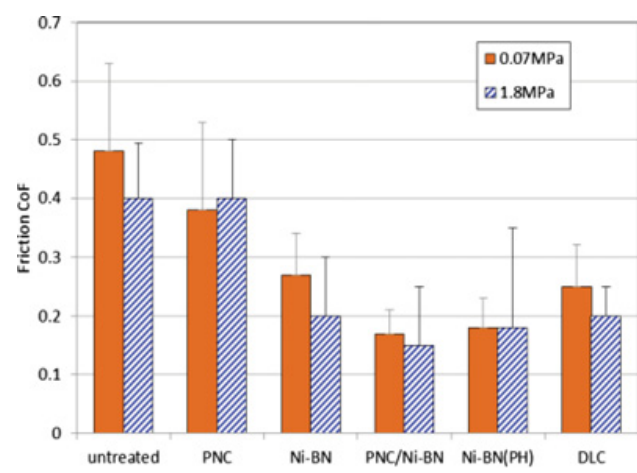

(a)

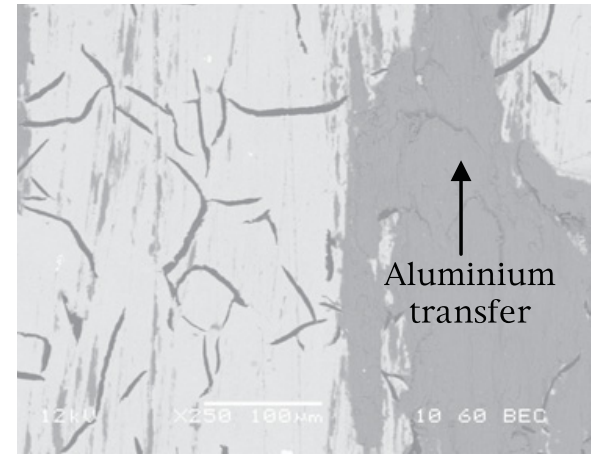

(b)

Figure 4. Friction coefficient of surface treated cast iron surface against Al-6082 pin (a) and adhesion of Al pin on untreated cast iron (b).

Table 2. Durability and wear of engineered cast iron surfaces dry sliding against a hardened steel ball.

\begin{tabular}{|c|c|c|c|c|}
\hline \multirow{2}{*}{ Substrate } & \multicolumn{2}{|c|}{ Maximum cycles before surface failure } & \multirow{2}{*}{$\begin{array}{c}\text { Surface } \\
\text { hardness, GPa }\end{array}$} & $\begin{array}{c}\text { Material lost, } \\
\mu \mathbf{m}^{2}, \mathbf{3 3 7} \mathbf{~ M P a}\end{array}$ \\
\cline { 2 - 3 } & $\mathbf{3 3 7} \mathbf{M P a}$ & $\mathbf{4 8 1} \mathbf{~ M P a}$ & 3.28 & 78 \\
\hline Untreated & - & - & 12.30 & 8 \\
\hline PNC & - & - & 5.20 & 60 \\
\hline Ni-BN & 153 & 59 & 8.16 & 11 \\
\hline Ni-BN(PH) & $>200$ & 78 & 16.00 & 2 \\
\hline DLC & $>200$ & $>200$ & 5.60 & 48 \\
\hline PNC/Ni-BN & $>200$ & 150 & & \\
\hline
\end{tabular}

In contrast, the self-lubrication surfaces developed can retard the transfer of $\mathrm{Al}$ because of the changed tribopair from metal/metal to metal/non-metal.

\subsubsection{Wear of engineered cast iron surfaces}

Wear is another important property determining the tool life but it is difficult to quantitatively measure under practical stamping conditions. Therefore, comparative wear studies were conducted on the surface treated G3500 gray cast iron during long-term sliding wear using a relatively hard steel ball. Table 2 shows the maximum cycles of all treated cast iron surfaces under the pressure of 337 and $481 \mathrm{MPa}$ before the monitored friction coefficient rises rapidly, which is an indication of failure of the engineered cast iron surfaces. It can be seen that under a load of $337 \mathrm{MPa}$, the Ni-BN sample can survive 153 cycles but all the other treated surfaces can withstand $>200$ cycles. However, when the load increased to $481 \mathrm{MPa}$, the maximum cycles that Ni-BN and Ni-BN (PH) dropped to 59 and 78 cycles respectively. This decrease in durability could be related to the soft cast iron substrate as the durability of Ni-BN coating on the plasma nitrocaburised substrate PNC/Ni-BN was still maintained at the high level of 150 cycles. This demonstrates the importance of the hardening of G3500 gray cast iron substrate to avoid so-called 'thin-ice' effect of relatively thin coatings.

It can be also clearly seen from Table 2 that plasma nitrocaburising can effectively reduce the wear of G3500 gray cast iron by about 10 times. Even for the coated cast iron surfaces, the material lost is also related to their hardness (Table 2). This is evidenced by comparing the hardness of Ni-BN and Ni-BN 


\section{MATEC Web of Conferences}

$(\mathrm{PH})$ and their wear lost, which indicated that post-hardening is useful for increasing the hardness and hence the wear resistance of Ni-BN.

\section{Conclusions}

Based on the experimental work conducted on the microstructural characterisation and tribological studies of the surface engineered G3500 gray cast iron, the following conclusions can be drawn:

- A range of surface engineering techniques including plasma nitrocraburising (PNC), electroless Ni-BN plating, PVD DLC coating and duplex treatment combining PNC with Ni-BN coating have been successfully applied to G3500 gray cast iron.

- When sliding against an Al pin at room temperature without lubrication, PNC treated and untreated samples are characterised by a high $(0.45-0.50)$ average coefficient of friction $(\mathrm{CoF})$ with large fluctuation due to the transfer of $\mathrm{Al}$ from the pin to the tested surfaces. In contrast, Ni-BN and DLC coated surfaces showed a much lower CoF of 0.15-0.25.

- Plasma nitrocraburising can effectively reduce the wear of G3500 gray cast iron sliding against a hardened steel ball by about 10 times mainly due to the formation of surface compound layer and the hardened subsurface.

- Pre-hardening by PNC can effectively increase the load bearing capacity of Ni-BN coating in the duplex surface system. Hence, it follows that the duplex system based on PCN followed by Ni$\mathrm{BN}$ coating is promising for improving the performance and life of cast iron dies for aluminium stamping.

The research was funded by the EU FP7 LOCoLite project (Contract No. GA604240).

\section{References}

[1] Metal Forming and Stamping Presses Improve productivity and safety in forming and stamping applications. Rockwell automation, Inc. 24/04/2015; Available from: http://literature. rockwellautomation.com/ (2013)

[2] E. Billur, Stamping Journal (2010)

[3] Y. Sun and T. Bell, Materials Science and Engineering a-Structural Materials Properties Microstructure and Processing, 140: p. 419-434 (1991)

[4] H. Dong and T. Bell, Surface and Coatings Technology, 111: p. 29-40 (1999)

[5] A. Mihail and M. Rodzik, Great designs in steel (2007)

[6] G.W. Stachowiak and A.W. Batchelor, Engineering Tribology (Third Edition), G.W. Stachowiak and A.W. Batchelor, Editors., Butterworth-Heinemann: Burlington. p. 419-459 (2006)

[7] D.T. Fraser and M.Z. Jahedi. 6th international tooling conference. Karlstad University (2002)

[8] P.F. Mendez and A.C. Powell, Scripta Materialia, 59: p. 784-787 (2008)

[9] E. Rolinski, Surface Engineering 3: p. 35-40 (1987)

[10] K. Agarwal, R. Shivpuri, J. Vincent, E. Rolinski, et al., Journal of Materials Processing Technology, 213: p. 864-876 (2013)

[11] E. Rolinski, A. Konieczny and G. Sharp, Journal of Materials Engineering and Performance, 18: p. 7 (2009)

[12] G. Nicoletto, A. Tucci and L. Esposito, Wear, 197: p. 38-44 (1996)

[13] E. Billur, Stamping Journal (2010)

[14] E. Rolinski, A. Konieczny and G. Sharp, Heat treating progress, 7: p. 39-46 (2007)

[15] K. Lukaszkowicz, J. Sondor, K. Balin and J. Kubacki, Applied Surface Science, 312: p. 126-133 (2014) 